\title{
Influence of changing carbonate chemistry on morphology and weight of coccoliths formed by Emiliania huxleyi
}

\author{
L. T. Bach ${ }^{1}$, C. Bauke ${ }^{2}$, K. J. S. Meier ${ }^{2}$, U. Riebesell ${ }^{1}$, and K. G. Schulz ${ }^{1}$ \\ ${ }^{1}$ Helmholtz-Zentrum für Ozeanforschung Kiel (GEOMAR), Düsternbrooker Weg 20, 24105 Kiel, Germany \\ ${ }^{2}$ Christian-Albrechts-Universität zu Kiel, Institute of Geosciences, Ludewig-Meyn-Str. 10, 24118 Kiel, Germany
}

Correspondence to: L. T. Bach (lbach@geomar.de)

Received: 6 March 2012 - Published in Biogeosciences Discuss.: 23 May 2012

Revised: 28 July 2012 - Accepted: 6 August 2012 - Published: 30 August 2012

\begin{abstract}
The coccolithophore Emiliania huxleyi is a marine phytoplankton species capable of forming small calcium carbonate scales (coccoliths) which cover the organic part of the cell. Calcification rates of E. huxleyi are known to be sensitive to changes in seawater carbonate chemistry. It has, however, not yet been clearly determined how these changes are reflected in size and weight of individual coccoliths and which specific parameter(s) of the carbonate system drive morphological modifications. Here, we compare data on coccolith size, weight, and malformation from a set of five experiments with a large diversity of carbonate chemistry conditions. This diversity allows distinguishing the influence of individual carbonate chemistry parameters such as carbon dioxide $\left(\mathrm{CO}_{2}\right)$, bicarbonate $\left(\mathrm{HCO}_{3}^{-}\right)$, carbonate ion $\left(\mathrm{CO}_{3}^{2-}\right)$, and protons $\left(\mathrm{H}^{+}\right)$on the measured parameters. Measurements of fine-scale morphological structures reveal an increase of coccolith malformation with decreasing $\mathrm{pH}$ suggesting that $\mathrm{H}^{+}$is the major factor causing malformations. Coccolith distal shield area varies from about 5 to $11 \mu \mathrm{m}^{2}$. Changes in size seem to be mainly induced by varying $\left[\mathrm{HCO}_{3}^{-}\right]$and $\left[\mathrm{H}^{+}\right]$although influence of $\left[\mathrm{CO}_{3}^{2-}\right]$ cannot be entirely ruled out. Changes in coccolith weight were proportional to changes in size. Increasing $\mathrm{CaCO}_{3}$ production rates are reflected in an increase in coccolith weight and an increase of the number of coccoliths formed per unit time. The combined investigation of morphological features and coccolith production rates presented in this study may help to interpret data derived from sediment cores, where coccolith morphology is used to reconstruct calcification rates in the water column.
\end{abstract}

\section{Introduction}

Coccolithophores are unicellular photoautotrophic organisms, able to form blooms in all major ocean basins (Moore et al., 2012). Their unique feature is the intracellular formation of small scales (coccoliths) made of calcium carbonate $\left(\mathrm{CaCO}_{3}\right)$ covering the organic surface of the cell. Coccolithophores appeared for the first time about 220 million years ago in the fossil record and are found ever since in marine sediments although their abundance was highly variable (Bown et al., 2004). They are important components in the marine carbon cycle because the $\mathrm{CaCO}_{3}$ in their coccoliths serves as ballasting material accelerating the organic carbon flux from the surface into the deep ocean (e.g. Honjo, 1976; Ploug et al., 2008). In modern oceans, Emiliania huxleyi is the most abundant species (Paasche, 2002). It evolved from Gephyrocapsa spec. about 291-270 kyr ago and dominates the coccolithophore community for the last $\sim 82-63 \mathrm{kyr}$ (Thierstein et al., 1977; Raffi et al., 2006). E. huxleyi frequently forms large blooms that can cover up to a million $\mathrm{km}^{2}$ and can be seen from space (Holligan et al., 1993; Tyrell and Young, 2009). These blooms are typically found in stratified waters during later stages of the phytoplankton spring succession (Tyrell and Merico, 2004), although, recently, high E. huxleyi abundance has also been reported in turbulent regimes when cell numbers are integrated over the whole water column (Schiebel et al., 2011).

The invasion of anthropogenic $\mathrm{CO}_{2}$ into the ocean currently changes the marine carbonate chemistry by increasing $\left[\mathrm{CO}_{2}\right]$ and decreasing seawater $\mathrm{pH}-\mathrm{a}$ process known as ocean acidification (Raven et al., 2005). Although these changes in carbonate chemistry are known to influence 
calcification rates of E. huxleyi (Riebesell and Tortell, 2011), it is still not understood how changing calcification rates are reflected in coccolith size, weight, and exocytosis rate (i.e. the number of coccoliths formed and egested per day). Such knowledge is, however, urgently needed for cases where morphometric data originating, for example, from sediment cores is used to reconstruct calcification rates within the water column. The influence of changing carbonate chemistry on the appearance of coccolith malformations in E. huxleyi is better understood (Langer et al., 2010, 2011) but key questions such as, for example, which carbonate chemistry parameter is actually causing malformations are still unknown.

The study presented here aims to improve our understanding on the following three research questions. (1) Does morphology (size and weight) of E. huxleyi (strain PML B92/11) coccoliths change in response to changing carbonate chemistry conditions? (2) Are potential changes in morphology reflected in calcium carbonate production rates? (3) Which particular carbonate chemistry parameter(s) drive potential changes in E. huxleyi coccolith morphology? In order to address these questions, we evaluated samples for E. huxleyi coccolith size, weight and malformation from five culture experiments with a large diversity of carbonate chemistry conditions. This diversity allowed us to disentangle the carbonate system and assess which of the carbonate system parameters that can directly influence the cell physiology (i.e. $\mathrm{CO}_{2}$, $\mathrm{HCO}_{3}^{-}, \mathrm{CO}_{3}^{2-}$ and $\mathrm{H}^{+}$) are responsible for possible changes in the morphology of coccoliths formed by E. huxleyi.

\section{Material and methods}

\subsection{Basic experimental settings}

Five experiments were conducted with monospecific cultures of the coccolithophore Emiliania huxleyi strain PML B92/11 (morphotype A), isolated in 1992 at the field station of the University of Bergen (Raunefjorden; $60^{\circ} 18^{\prime} \mathrm{N}, 05^{\circ} 15^{\prime} \mathrm{E}$ ). At this site, E. huxleyi usually blooms during late spring at typical surface water temperatures between $10-12{ }^{\circ} \mathrm{C}$ (compare Schulz et al., 2008). All experiments are generally similar in their design. Differences between them are exclusively manifested in the carbonate chemistry parameters of the culture medium (see Sect. 2.2).

All experiments were conducted with dilute batch cultures (LaRoche et al., 2010) at $15^{\circ} \mathrm{C}$ and $150 \mu \mathrm{mol}$ photons $\mathrm{m}^{-2} \mathrm{~s}^{-1}$ incident photon flux density in a 16/8 light/dark cycle. The growth medium was artificial seawater, prepared as described in Kester et al. (1967) but without the addition of $\mathrm{NaHCO}_{3}$. The artificial seawater medium (free of dissolved inorganic carbon (DIC) and total alkalinity (TA)) was enriched with $\sim 64 \mu \mathrm{mol} \mathrm{kg}^{-1}$ nitrate, $4 \mu \mathrm{mol} \mathrm{kg}^{-1}$ phosphate, $\mathrm{f} / 8$ concentrations for trace metals and vitamins (Guillard and Ryther, 1962), $2 \mathrm{ml} \mathrm{kg}^{-1}$ of natural North Sea water and $10 \mathrm{nmol} \mathrm{kg}^{-1}$ of $\mathrm{SeO}_{2}$ to avoid nutrient limitation in the course of the experiments. Samples for nitrate and phosphate were $0.7 \mu \mathrm{m}$ filtered at the beginning and the end of the experiments and measured according to Hansen and Koroleff (1999). The nutrient-enriched medium was sterile-filtered $(0.2 \mu \mathrm{m})$ into sterile polycarbonate bottles where the carbonate system was adjusted (see following section). Samples for carbonate chemistry measurements $(\sim 500 \mathrm{ml})$ were taken from these bottles after adjustment. The remaining medium was gently transferred into sterile 21 polycarbonate bottles. The headspace in the 21 bottles was kept below $5 \mathrm{ml}$. The culture medium was acclimated to $15^{\circ} \mathrm{C}$ overnight to avoid a thermal shock when transferring the cells from the pre-cultures to bottles in which the main experiments were performed. Cells were acclimated to the carbonate chemistry conditions of the main experiment for at least 7 generations prior to inoculation.

\subsection{Carbonate chemistry manipulations}

The experiments only differed with respect to the carbonate chemistry manipulation of the culture medium. In the first experiment, cells were cultured at constant total alkalinity $\left(2320 \pm 22 \mu \mathrm{mol} \mathrm{kg}{ }^{-1}\right)$ and varying $f \mathrm{CO}_{2}$ levels, ranging from $\sim 20$ to $\sim 5960 \mu \mathrm{atm}$. Here, DIC and TA levels were adjusted by adding calculated amounts of $\mathrm{Na}_{2} \mathrm{CO}_{3}$ and hydrochloric acid $\left(3.571 \mathrm{moll}^{-1}\right.$, certified by Merck) (Gattuso et al., 2010). In the second, third and fourth experiment, $\mathrm{pH}$ was kept constant at $\mathrm{pH}_{\mathrm{f}}$ (free scale) $7.74( \pm 0.004), 8( \pm 0.01)$, and $8.34( \pm 0.008)$, while $f \mathrm{CO}_{2}$ was increased from $\sim 100$ to $\sim 3600$, from $\sim 40$ to 3650 , and from $\sim 21$ to $\sim 1163 \mu \mathrm{atm}$, respectively. Carbonate chemistry in the constant $\mathrm{pH}$ approaches was adjusted by adding $2 \mathrm{mmol} \mathrm{kg}^{-1}$ of 2-[-4-(2-Hydroxyethyl)1-piperazinyl]-ethanesulfonic acid (HEPES) to the culture medium, which was adjusted to the target $\mathrm{pH}_{\mathrm{f}}$ levels. DIC was added as $\mathrm{NaHCO}_{3}$. The small change in $\mathrm{pH}$ in the HEPES buffered seawater medium due to $\mathrm{NaHCO}_{3}$ addition was compensated by adding small amounts of strong $\mathrm{NaOH}$ or $\mathrm{HCl}$. In the fifth experiment, $f \mathrm{CO}_{2}$ was kept constant ( $430 \pm 47 \mu \mathrm{atm})$, while DIC ranged from $\sim 500$ to $4100 \mu \mathrm{mol} \mathrm{kg}{ }^{-1}$. DIC and $f \mathrm{CO}_{2}$ were adjusted by adding calculated amounts of $\mathrm{Na}_{2} \mathrm{CO}_{3}$ and hydrochloric acid (Gattuso et al., 2010). For an overview of carbonate chemistry conditions in all treatments, see Fig. 1 and Table 1. Note that each culture bottle is considered as an individual treatment in our data analysis and the errors given in Fig. 1 and Table 1 denote the change in carbonate chemistry speciation within the culture bottle from the beginning to the end of the experiment.

\subsection{Carbonate chemistry sampling and measurements}

Samples for TA measurements were filtered $(0.7 \mu \mathrm{m})$, poisoned with a saturated $\mathrm{HgCl}_{2}$ solution $(0.5 \%$ o final concentration) and stored at $4{ }^{\circ} \mathrm{C}$ until measurements. TA was 


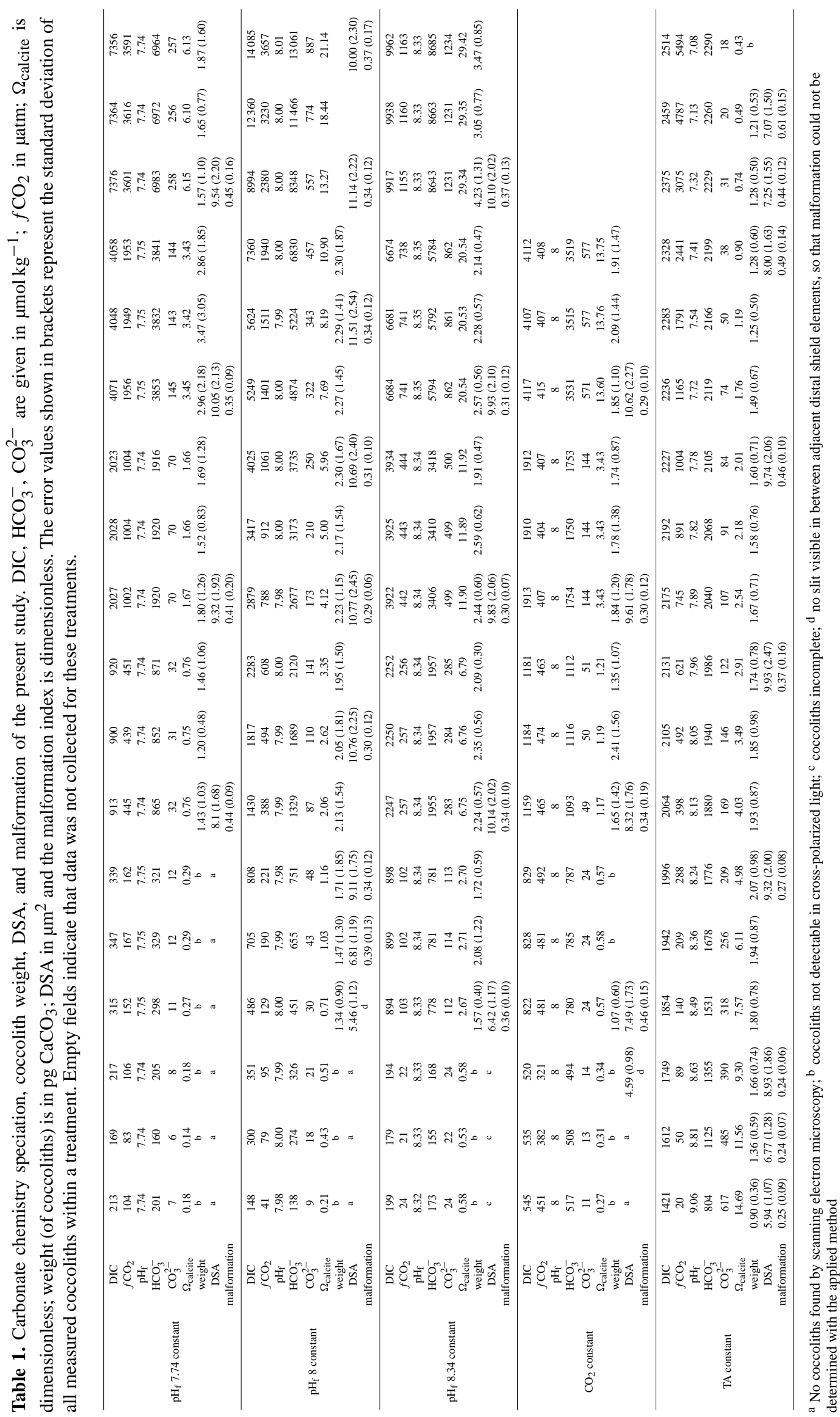



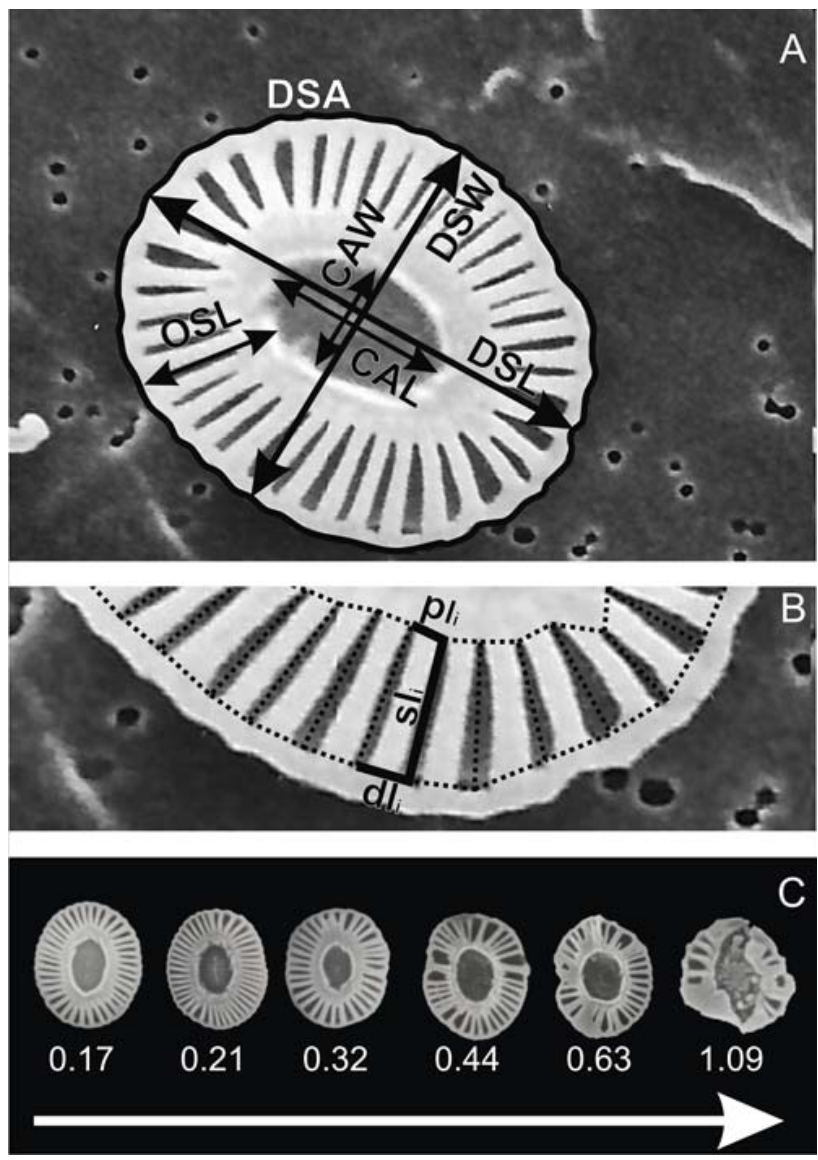

Fig. 1. Morphological quantities measured by SEM. (A) Measured size attributes, distal shield area (DSA), distal shield length (DSL), distal shield width (DSW), central area length (CAL), central area width (CAW), and outer shield length (OSL). (B) Measurements for calculation of malformation index, proximal distance between two adjacent slits ( $\mathrm{pl})$, length of slit ( $\mathrm{sl}$ ), and distal distance between two adjacent slits (dl). pl, sl, and dl were measured for each slit of the investigated coccolith and then processed with Eq. (8). (C) Examples of coccoliths with corresponding malformation calculated from Eq. (8). The arrow indicates increasing malformation.

measured in duplicate applying a two-stage potentiometric open cell titration (Dickson et al., 2003) and corrected with certified reference material (A. Dickson, La Jolla, CA). Some TA samples of the constant $\mathrm{CO}_{2}$ experiment were higher than $\sim 4700 \mu \mathrm{mol} \mathrm{kg}{ }^{-1}$ and had to be diluted in order to get reliable results. Therefore, these TA samples were mixed with double de-ionised water, containing no alkalinity. The ratio of double de-ionised water relative to the TA sample was determined on a balance (Sartorius) with a precision of $\pm 0.01 \mathrm{~g}$.

Samples for DIC were sterile filtered $(0.2 \mu \mathrm{m})$ with gentle pressure and stored bubble-free at $4{ }^{\circ} \mathrm{C}$ in $4 \mathrm{ml}$ borosilicate bottles. All DIC samples were measured according to Stoll et al. (2001). In most treatments of the constant $\mathrm{pH}$ experiments, DIC was either too high or too low to be measured according to Stoll et al. (2001). To solve this problem, sample medium was mixed with artificial seawater of known DIC concentration. The ratio of the mixing solvent to the original DIC sample was determined by first weighing the mixing solvent alone, and in a second step by weighing the mixing solvent plus the original DIC sample on a balance with a precision of $\pm 0.01 \mathrm{mg}$ (Sartorius). The mixture was carefully rotated in a $50 \mathrm{ml}$ tube with $\sim 1 \mathrm{ml}$ headspace. The ratio of sample to mixing solvent was adjusted to result in a final DIC concentration of approximately $1800-2200 \mu \mathrm{mol} \mathrm{kg}{ }^{-1}$. After the mixing procedure, DIC samples were processed identical to undiluted samples (see above).

Samples for $\mathrm{pH}_{\mathrm{f}}$ were measured potentiometrically at $15^{\circ} \mathrm{C}$ with separate glass and reference electrodes (Metrohm) which were calibrated with reference material certified for TA and DIC with a salinity of 33.3 (A. Dickson, La Jolla, $\mathrm{CA}$ ). $\mathrm{pH}_{\mathrm{f}}$ of the reference material was calculated from certified TA and DIC applying the constants of Roy et al. (1993). Measured electromotive force $(E)$ of the samples and standards were used to calculate the $\mathrm{pH}_{\mathrm{f}}$ of the sample as

$$
\mathrm{pH}_{\mathrm{f}}=\mathrm{pH}_{\mathrm{f} \text { ref }}+\frac{E_{\mathrm{s}}-E_{\mathrm{x}}}{R \times T \times \frac{\ln 10}{F}},
$$

where $\mathrm{pH}_{\mathrm{f}}$ ref is the calculated $\mathrm{pH}_{\mathrm{f}}$ of the certified reference material, $T$ is the temperature of the sample in Kelvin, $R$ is the universal gas constant, $F$ the Farady constant and $E_{\mathrm{s}}$ and $E_{\mathrm{x}}$ are the measured electromotive forces in volts of the standard and the sample, respectively, (Dickson et al., 2007).

\subsection{DIC estimations}

Unfortunately, we lost all DIC measurements of the constant TA experiment and the DIC measurements from the beginning of constant $\mathrm{pH}_{\mathrm{f}} 8$ experiment due to storage problems. The estimation of DIC of these samples is shown in detail in Bach et al. (2011) and shall be outlined only briefly in the following. DIC concentrations from the beginning of the constant $\mathrm{pH}_{\mathrm{f}} 8$ experiment were estimated by adding the total particulate carbon build-up, which was produced during the experiment, to the final DIC concentrations. Initial DIC concentrations from the constant TA experiment were calculated as

$\mathrm{DIC}=\frac{\mathrm{TA}_{\text {measured }}+\left(\text { Volume }_{\text {acid }} \times 3.571\right)}{2}$,

where $\mathrm{TA}_{\text {measured }}$ is the measured TA in $\mu \mathrm{mol} \mathrm{kg}-1$ at the beginning of the experiment, Volume ${ }_{\text {acid }}$ is the volume of acid that was added in $\mu \mathrm{kg}^{-1}$ and 3.571 is the molarity of the acid (certified by Merck) in mol $\mathrm{l}^{-1}$. This estimate has an uncertainty of approximately $40-50 \mu \mathrm{mol} \mathrm{kg}{ }^{-1}$, which is small compared to the large DIC range in this experiment (Bach et al., 2011). DIC concentrations at the end of the constant TA experiment were calculated by subtracting the measured total particulate carbon build-up from the initial DIC concentrations. 


\subsection{Carbonate chemistry calculations}

Carbonate chemistry conditions within experiments were calculated from temperature, salinity, inorganic phosphate concentrations and two measured (or estimated) carbonate system parameters, applying the equilibrium constants of Roy et al. (1993) and the program CO2Sys (Lewis and Wallace, 1998). Measured (or estimated) carbonate system parameters were the following: TA and DIC in the constant TA experiment; $\mathrm{pH}_{\mathrm{f}}$ and $\mathrm{DIC}$ in the constant $\mathrm{pH}$ experiments; and $\mathrm{TA}$ and $\mathrm{pH}_{\mathrm{f}}$ in the constant $\mathrm{CO}_{2}$ experiment. The biological response data are plotted to the mean of initial and final carbonate chemistry conditions.

\subsection{Sampling and calculation of coccolith exocytosis rate}

Sampling started two hours after the onset of the light period and lasted no longer than two and a half hours. Two samples for particulate organic carbon (POC) and two for total particulate carbon (TPC) were filtered $(200 \mathrm{mbar})$ onto precombusted $\left(5 \mathrm{~h}, 500^{\circ} \mathrm{C}\right) \mathrm{GF} / \mathrm{F}$ filters and stored in the dark at $-20^{\circ} \mathrm{C}$. POC and TPC samples from constant $\mathrm{pH}$ experiments were rinsed with artificial seawater (supersaturated with respect to calcite) before freezing at $-20{ }^{\circ} \mathrm{C}$ in order to wash off HEPES buffer which otherwise would have contributed $\sim 40$ pg of carbon to every TPC and POC measurement. POC samples were stored for two hours in a desiccator containing fuming $\mathrm{HCl}$ to remove all inorganic carbon and subsequently dried for $\sim 6 \mathrm{~h}$ at $60^{\circ} \mathrm{C}$. TPC filters were dried in the same way as the POC filters, but in a separate oven and without prior acid treatment. Carbon concentrations of POC and TPC filters were measured using an isotope ratio mass spectrometer (Finnigan) combined with an elemental analyzer (EuroEA, Hekatech $\mathrm{GmbH}$ ). Particulate inorganic carbon (PIC) was calculated as the difference between TPC and POC. Four POC samples from the constant $\mathrm{pH}_{\mathrm{f}} 8$ experiment were lost during measurements.

Cell numbers were measured at the beginning and the end of the experiment with a Coulter Counter (Beckmann). The growth rate $(\mu)$ was calculated from initial and final cell numbers as

$\mu=\frac{\ln \left(t_{\text {fin }}\right)-\ln \left(t_{0},\right)}{d}$

where $t_{0}$ and $t_{\text {fin }}$ is the cell number at beginning and the end of the experiment, respectively, and $d$ is the number of days the cell culture was growing. PIC production rates were calculated by multiplying $\mu$ and $\mathrm{PIC}$ cell ${ }^{-1}$. $\mathrm{CaCO}_{3}$ production rates were calculated by multiplying PIC production rates (in $\mu$ mol C cell ${ }^{-1} \mathrm{~d}^{-1}$ ) with the molecular weight of $\mathrm{CaCO}_{3}$. The number of egested coccoliths per day was subsequently determined as

coccolith exocytosis rate $=\frac{\mathrm{CaCO}_{3} \text { production rates }}{\text { coccolith weight }}$, where coccolith weight was measured as described in Sect. 2.8.

\subsection{Scanning electron microscopy (SEM)}

From $5-10 \mathrm{ml}$ of sample were filtered by gravity on polycarbonate filters $(0.2 \mu \mathrm{m}$ pore size). Samples taken from the constant TA and the constant $\mathrm{pH}_{\mathrm{f}} 8$ experiment were dehydrated with ethanol and bis(trimethylsilyl)amine solution to conserve the organic part of the cell, and then subsequently dried in a desiccator (Bach et al., 2011). Samples for the other three experiments were dried directly after filtration at $60^{\circ} \mathrm{C}$. All samples were kept in the desiccator until they were sputtered with gold-palladium and processed with the scanning electron microscope.

SEM pictures were taken with a CamScan CS 44 scanning electron microscope and evaluated using the software imageJ. Measured lengths or areas on the pictures were calibrated with the size bar given on each SEM picture. Manually measured parameters on coccoliths were the surface area of the distal shield (DSA), the length of the distal shield (DSL), the width of the distal shield (DSW), the length of the central area (CAL) and the width of the central area (CAW) (compare Fig. 1a). CAL and CAW could not be determined in cases where the coccolith was lying upside down on the filter. On average, 82 coccoliths per sample were investigated for DSA, DSL and DSW and 36 for CAL and CAW. Note that not all treatments could be investigated with SEM due to the extremely elaborate manual evaluation. Evaluated treatments are shown in Table 1.

Measured DSA was compared to an estimated value calculated from DSL and DSW as

calculated DSA $=\pi \times \frac{\mathrm{DSL} \times \mathrm{DSW}}{4}$

assuming an elliptical shape of the coccolith. The outer shield length (OSL) was calculated as

$\mathrm{OSL}=\frac{\mathrm{DSL}-\mathrm{CAL}+\mathrm{DSW}-\mathrm{CAW}}{4}$.

\subsection{Determination of coccolith weight by birefringence}

From $5-10 \mathrm{ml}$ of sample were filtered with $\sim 100$ mbar on a cellulose nitrate filter $(0.45 \mu \mathrm{m}$ pore size). Filters were dried for $2 \mathrm{~h}$ at $60^{\circ} \mathrm{C}$ and subsequently embedded with Acrifix 192 (Roehm) on microscope slides. Acrifix makes cellulose nitrate filters transparent without damaging the coccoliths and has a refraction index of 1.44 , so that it does not interfere with the optical analysis.

Images of coccoliths were taken with a Leica DM6000B light microscope equipped with a SPOT Insight b/w camera. Under cross-polarized light only the birefringent calcite of the coccoliths is illuminated. A total 200 images were randomly taken per sample and analyzed with the software 

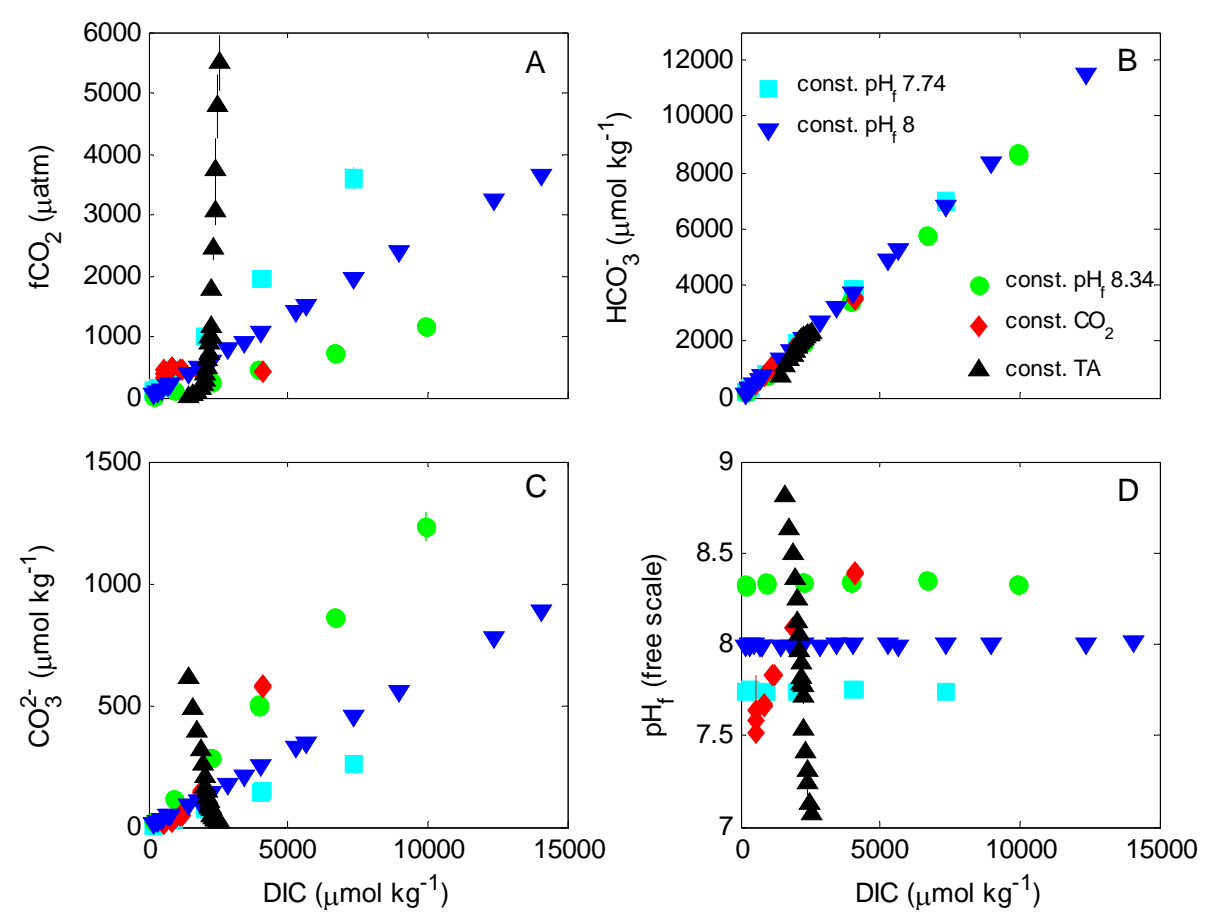

Fig. 2. Carbonate chemistry speciation in relation to DIC. Error bars denote the change in carbonate chemistry from the beginning to the end of the experiment. Note that error bars are in most cases masked by symbol size. (A) $f \mathrm{CO}_{2} ;(\mathbf{B}) \mathrm{HCO}_{3}^{-} ;(\mathbf{C}) \mathrm{CO}_{3}^{2-} ;(\mathbf{D})$ pH $\mathrm{f}$. Symbol and colour coding are shown in panel (B).

SYRACO (Beaufort and Dollfus, 2004). The software identifies E. huxleyi coccoliths and measures the grey level for each pixel. Coccolith weight was subsequently calculated from measured grey level following Beaufort et al. (2008). On average, $\sim 500$ coccoliths were evaluated for coccolith weight per sample.

\subsection{Calculation of malformation}

Coccolith malformation has been defined as "irregular coccolith formation as a result of departure from the normal growth process" and is commonly expressed in reduced symmetry or altered shape of individual elements (Young and Westbroek, 1991). In order to meet the demands given in this definition, fine-scale morphological structures of individual coccoliths were measured and subsequently used in an algorithm to quantify the degree of malformation. The measured morphological quantities comprised vectors associated to the openings between distal shield elements (slits). These measured quantities were the following: (1) the distances between the distal ends of two adjacent slits (dl); (2) the distances between the proximal ends of two adjacent slits (pl); and (3) the length of each slit (sl) (compare Fig. 1b). Incomplete coccoliths were not measured.

In general, regular and repetitive structures like the individual elements composing a coccolith appear to be malformed in cases where these adjacent structures differ in an irregular manner. Malformations are therefore characterized in the evaluation procedure as the degree of asymmetry of adjacent slits.

The algorithm to calculate the malformation index makes use of the average deviation. It is defined as

Average deviation $=\frac{1}{n} \sum_{i=1}^{n} \mid x_{i}-$ mean $(x)_{n} \mid$,

where $n$ is the number of all measured elements, $x_{i}$ is a measured element and mean $(x)_{n}$ is the mean value of all measured elements. Using the average deviation has the advantage that it is not influenced by the number of measured elements. Hence, the malformation index is not sensitive to the number of distal shield elements of the investigated coccolith. Applying the average deviation, the degree of malformation is calculated as 

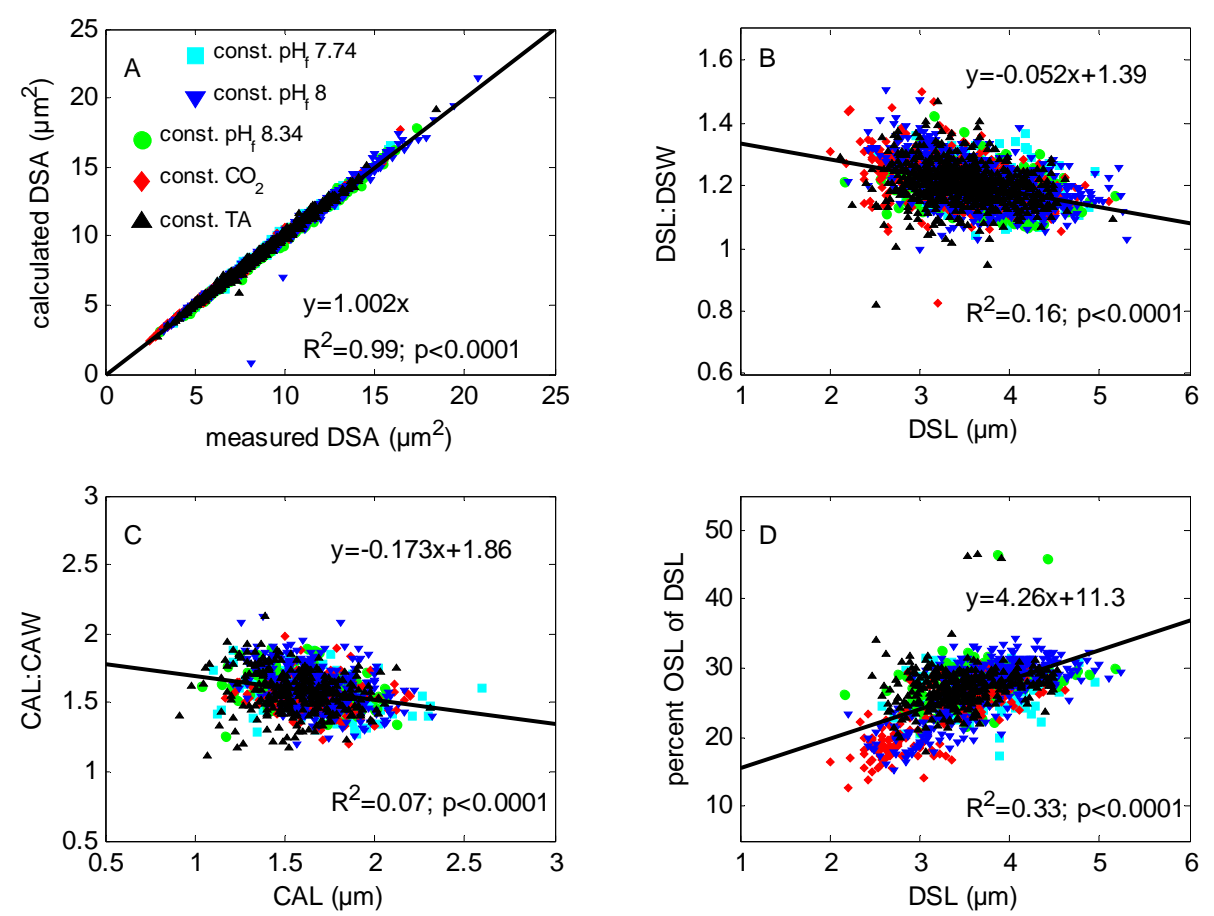

Fig. 3. Morphology of coccoliths. Each data point represents an individual coccolith. (A) Correlation between measured DSA and DSA calculated from DSL and DSW using Eq. (4). (B) Aspect ratio of distal shield with increasing DSL. (C) Aspect ratio of central area with increasing CAL. (D) Percentage of OSL that contributes to the total DSL. Symbol size and colour coding is shown in panel (A).

$$
\begin{aligned}
\text { Malformation }= & \frac{1}{n} \sum_{i=1}^{n} \mid \frac{\left|d l_{i}-d l_{i+1}\right|}{\frac{1}{2}\left(d l_{i}+d l_{i+1}\right)} \\
& -\operatorname{mean}\left(\frac{\left|d l_{i}-d l_{i+1}\right|}{\frac{1}{2}\left(d l_{i}+d l_{i+1}\right)}\right)_{n} \mid \\
& +\frac{1}{n} \sum_{i=1}^{n} \mid \frac{\left|s l_{i}-s l_{i+1}\right|}{\frac{1}{2}\left(s l_{i}+s l_{i+1}\right)} \\
& -\operatorname{mean}\left(\frac{\left|s l_{i}-s l_{i+1}\right|}{\frac{1}{2}\left(s l_{i}+s l_{i+1}\right)}\right){ }_{n} \mid \ldots \\
& +\frac{1}{n} \sum_{i=1}^{n} \mid \frac{\left|p l_{i}-p l_{i+1}\right|}{\frac{1}{2}\left(p l_{i}+p l_{i+1}\right)} \\
& - \text { mean }\left(\frac{\left|p l_{i}-p l_{i+1}\right|}{\frac{1}{2}\left(p l_{i}+p l_{i+1}\right)}\right)_{n} \mid,
\end{aligned}
$$

where $d l, s l$ and $p l$ are the measured quantities of the distal shield elements (see above) and $n$ is the total number of slits. In this way, higher values calculated from Eq. (8) reflect increased malformation (Fig. 1c). On average, 27 coccoliths were evaluated per sample with Eq. (8).

\section{Results}

\subsection{Carbonate chemistry}

A large diversity of carbonate chemistry conditions was set up in the five experiments presented in this study. In each one of the five experiments, one particular carbonate system parameter was kept constant while all the others changed with increasing DIC (Fig. 2). In the constant TA experiment, $f \mathrm{CO}_{2}$ and $\left[\mathrm{HCO}_{3}^{-}\right]$increased, while $\mathrm{pH}$ and $\left[\mathrm{CO}_{3}^{2-}\right]$ decreased with increasing DIC. The carbonate system manipulation of this experiment is similar to the way seawater carbonate chemistry is currently changing due to anthropogenic $\mathrm{CO}_{2}$ invasion. In the three constant $\mathrm{pH}$ experiments, all carbonate system parameters except for $\mathrm{pH}_{\mathrm{f}}$ were increasing linearly with increasing DIC. $\mathrm{pH}_{\mathrm{f}}$ remained constant in all of these experiments but at different levels. In the constant $\mathrm{CO}_{2}$ experiment, all carbonate system parameters except for $\mathrm{CO}_{2}$ were increasing with DIC.

\subsection{General morphological features}

Measured and calculated DSA are in excellent agreement to each other. The slope of the linear regression is close to one, which shows that DSA can reliably derived from DSL and DSW (Fig. 3a). The aspect ratio of the coccolith (i.e. DSL:DSW) gets closer to one with increasing coccolith length, indicating that larger coccoliths are rounder than 


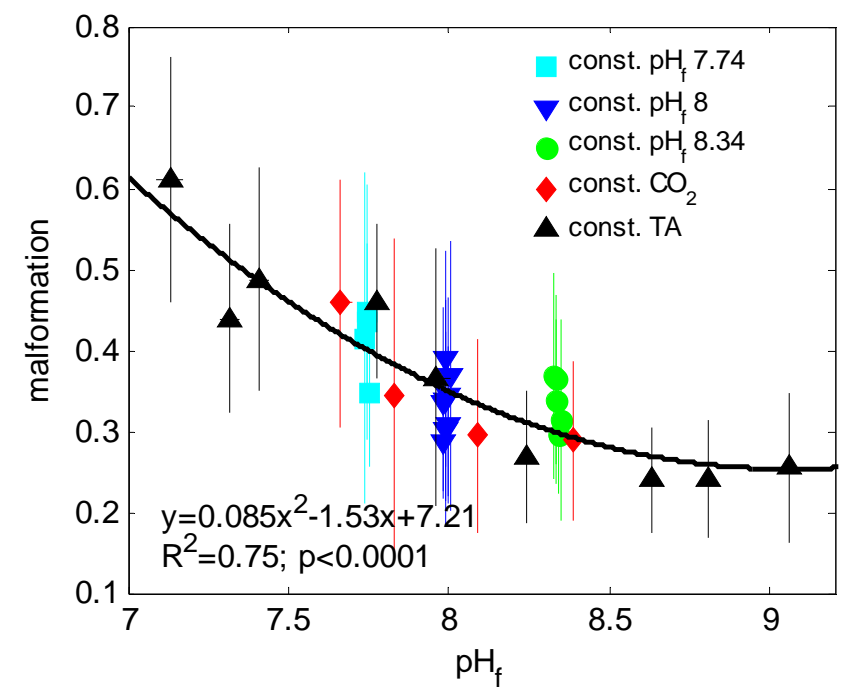

Fig. 4. Malformation of coccoliths calculated with Eq. (8). Error bars denote the standard deviation from measured mean malformation of all coccoliths in a treatment.

smaller ones (Fig. 3b). The same trend was found for the aspect ratio of the central area. The larger the central area became, the rounder it was (Fig. 3c), which is in good agreement with results obtained by Young and Westbroek (1991). The relative contribution of OSL to total DSL increased with increasing DSL (Fig. 3d).

\subsection{Malformation}

Malformations of coccoliths correlated best to seawater $\mathrm{pH}_{\mathrm{f}}$, indicating a key influence of $\mathrm{H}^{+}$. Malformations remained relatively stable above a $\mathrm{pH}_{\mathrm{f}}$ of about 8 , whereas they increased with decreasing $\mathrm{pH}_{\mathrm{f}}$ in the range from $\sim 8$ down to 7.1 (Fig. 4). $\mathrm{CaCO}_{3}$ production rates did not correlate with malformations (data not shown), suggesting that the appearance of malformations is not coupled to calcification rates in E. huxleyi.

\subsection{Coccolith size}

Changes in DSA, DSL and DSW in response to varying carbonate chemistry conditions were largely identical to each other. All three parameters increased most pronounced in the range from low to intermediate $\left[\mathrm{HCO}_{3}^{-}\right]$or $f \mathrm{CO}_{2}$, whereas changes were minor above this threshold in all except the constant TA experiment where a decreasing trend above $\sim 1000 \mu$ atm was observed (Fig. 5a-d; data for DSW not shown).

The smallest coccoliths were measured at very low $\mathrm{HCO}_{3}^{-}$ of $\sim 500 \mu \mathrm{mol} \mathrm{kg}^{-1}$ (Fig. 5; Table 1). These carbonate chemistry conditions are unrealistically low and most likely rarely existed in the natural habitat of E. huxleyi since its appearance about $270 \mathrm{ky}$ ago. Hence, sizes determined in these par- ticular treatments should be considered as physiological potentials rather than realistic representations of naturally occuring E. huxleyi coccolith sizes. Variations in size were minor within a realistic DIC and $f \mathrm{CO}_{2}$ range of the last $270 \mathrm{ky}$ (i.e. from present conditions down to about $1800 \mu \mathrm{mol} \mathrm{kg}{ }^{-1}$ and $180 \mu \mathrm{atm}$, respectively). DSA, for example, varied from about 8 to $9 \mu \mathrm{m}^{2}$ and showed no clear trend within that range if all experiments are considered. Note, however, that DSA increases in the constant TA experiment which simulates ocean acidification, from $\sim 180$ to $650 \mu$ atm by about $10 \%$ and starts to decrease slightly above this threshold.

$\mathrm{CAL}$ and CAW remained largely unaffected by changing carbonate chemistry except for the very lowest $f \mathrm{CO}_{2}$ levels in the constant TA experiment (below $\sim 100 \mu$ atm) where they showed a decreasing tendency (Fig. 5e and f).

\subsection{Coccolith weight and production}

The mean weight of coccoliths increased by approximately $100 \%$ from lowest to highest $\mathrm{CaCO}_{3}$ production rates (estimated from linear fit). Measured mean weight ranged from $\sim 1$ to 4 pg (Fig. 6a), which is in reasonable agreement with previous estimates of $\sim 2$ pg for the same E. huxleyi morphotype (Fagerbakke et al., 1994; Young and Ziveri, 2000). The coccolith exocytosis rate also increased with $\mathrm{CaCO}_{3}$ production by an estimated $100 \%$, similar as for coccolith weight. Minimum and maximum calculated coccolith exocytosis rates were $\sim 12$ and 45 coccoliths cell ${ }^{-1} \mathrm{~d}^{-1}$, respectively (Fig. 6b). Changes in coccolith weight correlate with changes in coccolith size (Fig. 6c).

In the three highest DIC treatments of the constant $\mathrm{pH} 8$ experiment, mean coccolith weight was up to $8 \mathrm{pg}$, which seems unrealistically high. After careful re-evaluation of SEM samples we occasionally found coccoliths that were associated with cubic crystals of unknown material. This might have caused interference with the coccolith weight estimation. Since we could not find a concomitant increase in the $\mathrm{CaCO}_{3}$ content per cell, we expect these values to be the result of non-biological processes.

\section{Discussion}

\subsection{Comparison of different evaluation methods of mal- formations}

Malformations of coccoliths in response to changing carbonate chemistry conditions have been observed in several coccolithophore species (e.g. Riebesell et al., 2000; Langer et al., 2006; Müller et al., 2010). In cases where these these malformations were quantified, it was done by visual comparisons of individual coccoliths and subsequent classifications to fixed categories like for example "normal", "slightly malformed", "strongly malformed", and "incomplete" (Langer et al., 2006, 2011; Kaffes et al., 2010; Bach et al., 2011). Here, we propose an alternative method to approximate 

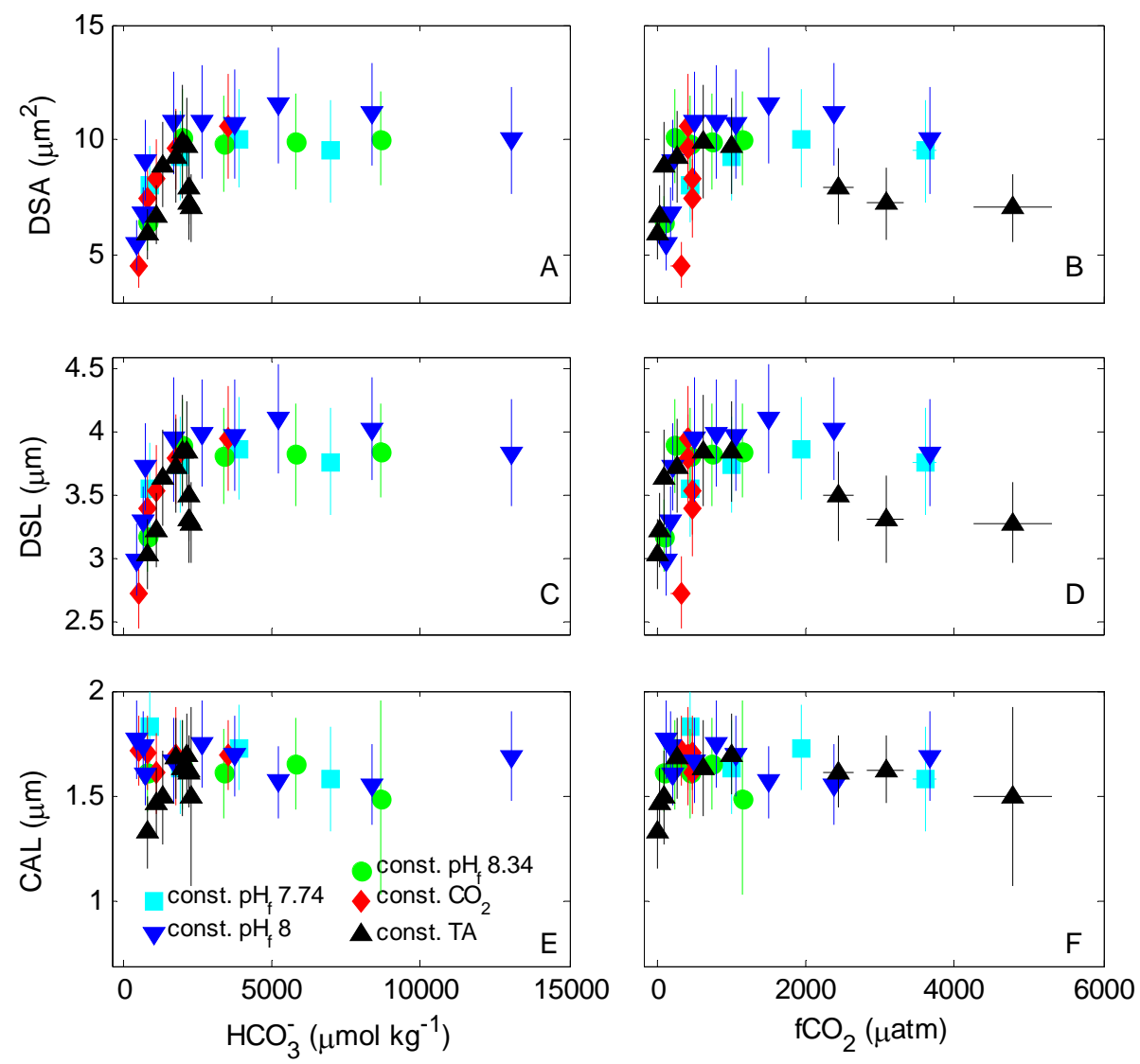

Fig. 5. Coccolith size (DSA, DSL, and DSW) as a function of carbonate chemistry speciation. (A), (C), (E) in relation to $\mathrm{HCO}_{3}^{-}$. (B), (D), (F) in relation to $\mathrm{fCO}_{2}$. Symbol size and color coding shown in panel (E). Error bars denote the standard deviation from measured mean size of all coccoliths in a treatment.

malformations of E. huxleyi, which aims to quantify malformations by direct measurements of fine-scale morphological structures (see Sect. 2.9). A direct comparison of both methods shows that they both lead to similar conclusions. Bach et al. (2011) have visually evaluated the same samples of the constant TA and the constant $\mathrm{pH}_{\mathrm{f}} 8$ experiment as used in this study and concluded that malformations are mainly induced by seawater $\mathrm{pH}_{\mathrm{f}}$ below $\sim 8$. This is largely confirmed by the results from the evaluation of malformation by Eq. (8) (Fig. 4), indicating that both methods seem to be equally appropriate to evaluate malformations of E. huxleyi.

The application of these two methods reveals distinct advantages of each. Visual evaluations can be done "online" during scanning of the sample by electron microscopy, whereas measurements of morphological structures require a time-intensive analysis of pictures taken by the microscope after having scanned the sample. Hence, visual evaluations facilitate analysis of high number of coccoliths per treatment and therefore usually lead to an investigation of a more representative sample size. Typically, 350 coccoliths per sample are evaluated by visual evaluations (e.g. Langer et al., 2011) in contrast to 27 evaluated coccoliths with the new method presented in our study. Furthermore, visual evaluations are easy to adapt to all coccolithophore species, whereas quantification of malformations by direct measurements of morphological structures can thus far only be applied to complete coccoliths from E. huxleyi morphotype A (including var. corona), $\mathrm{B}, \mathrm{C}$, and $\mathrm{O}$; but it cannot be applied to morphotype $\mathrm{R}$ since there are usually no slits between two adjacent distal shield elements in these morphotypes (for morphotype taxonomy see Young et al., 2003; Hagino et al., 2011). Although adaption of Eq. (8) to other species or morphotype $\mathrm{R}$ is generally possible, it would require measurements of other fine scale structures than the ones used in E. huxleyi. The major advantage of the new method is the reduction of subjectivity. A direct measurement of morphological structures reduces human influence on the measurement and makes it easier to compare with results of other studies. Furthermore, Eq. (8) could be implemented in an evaluation software which would analyze malformations automatically. This would be the most efficient and the most reproducible way to quantify malformations. 

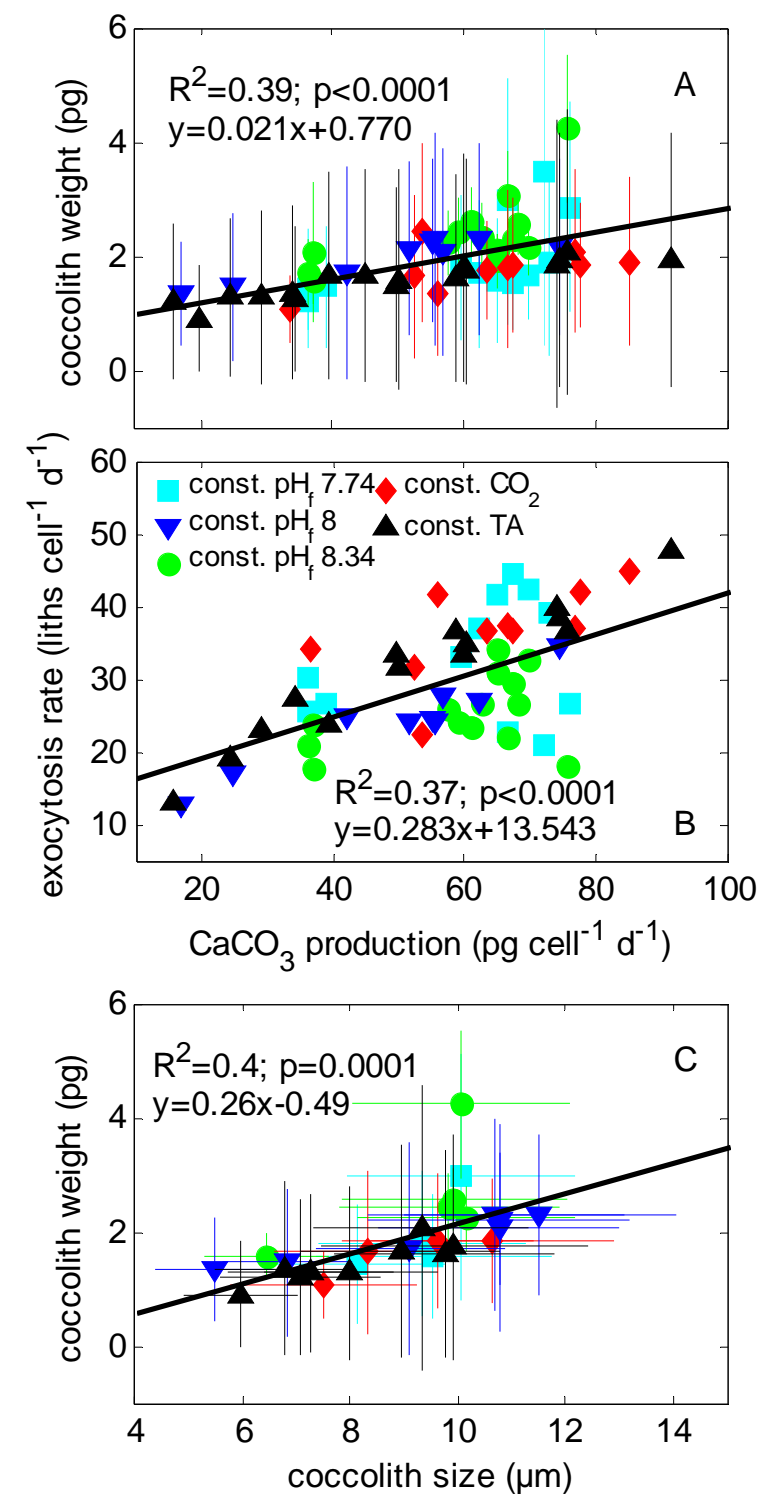

Fig. 6. Coccolith weight, production and size. (A) Correlation between cellular $\mathrm{CaCO}_{3}$ production rate and mean coccolith weight. (B) Correlation between cellular $\mathrm{CaCO}_{3}$ production rate and the number of coccoliths formed per day. (C) Correlation between coccolith size and weight. Error bars denote the standard deviation from measured mean weight or size of all coccoliths of a treatment. Regression line shows a fit through data from all experiments with fit equation and significance given in the figure. Note that the correlation does not apply equally well for individual experiments.

\subsection{Cause of malformations}

Malformations of E. huxleyi coccoliths are most likely induced by high concentrations of $\mathrm{H}^{+}$(Fig. 4). In order to understand how excess seawater $\left[\mathrm{H}^{+}\right]$could interfere with coccolith formation, it may be helpful to consider the development of a coccolith on a cellular basis. The formation takes place in a Golgi-derived vesicle (coccolith vesicle or
$\mathrm{CV}$ ) which is closely associated with a labyrinthine membrane system (reticular body). Coccolith formation is initiated inside the $\mathrm{CV}$ with the production of an organic base plate which serves as template (van der Wal et al., 1983; Westbroek et al., 1984, 1989; Young et al., 1999). Nucleation of calcite occurs subsequently on the rim of the organic base plate from where the initial crystals start to grow in a radial direction until coccolith formation is completed (Westbroek et al., 1984, 1989; Young et al., 1992). Crystal growth is tightly controlled by the cellular machinery. The inner side of the CV membrane always remains in close contact with the coccolith and is actively expanded from the outside by the cytoskeleton located within the cytosol so that the growing calcite crystals fill the space defined by the expanding vesicle (Westbroek et al., 1984, 1989; Didymus et al., 1994; Marsh et al., 1994; Young et al., 2009). Inside the CV, coccolithassociated polysaccharides (CAPs) bound to the inner side of the membrane, have a crucial role in controlling $\mathrm{CaCO}_{3}$ precipitation due to their potential to bind $\mathrm{Ca}^{2+}$ (De Jong et al., 1976) and inhibit precipitation at places where they cover the calcite (Borman et al., 1982; Henriksen et al., 2004).

Considering the pathway described above, the cytoskeleton and CAPs seem to be two major cellular components controlling the correct growth of calcite crystals within E. huxleyi (Young et al., 1999; Langer et al., 2006). Langer et al. (2010) examined in detail the consequences of a malfunctioning of the cytoskeleton on coccolith formation by applying chemical inhibitors for microtubules and actin filaments. They found an increasing degree of coccolith malformation the more these cytoskeleton structures and therefore the active expansion of the $\mathrm{CV}$ was disturbed by these inhibitors. Possibly, malformations found in our study are also resulting from a malfunctioning of the cytoskeleton, in our case with the chemical driving force being $\mathrm{H}^{+}$. This explanation seems plausible since $\mathrm{H}^{+}$is known to easily enter into the cytosol of E. huxleyi (Suffrian et al., 2011). Here, a change in $\left[\mathrm{H}^{+}\right]$could disturb the correct functioning of cytoskeleton elements or the enzymes associated with them so that the controlled expansion of the $\mathrm{CV}$ is handicapped (Langer et al., 2006).

The second possible option of a negative effect of $\mathrm{H}^{+}$ on crystal growth is a disturbance of CAPs inside the CV (Langer et al., 2006, 2011). Henriksen and Stipp (2009) demonstrated that the capability of CAPs to bind onto calcite crystals depends on the ion composition of the solution in which CAPs are dissolved. A change of the ion composition inside the CV may therefore disturb controlled crystal growth. Such a change could be the direct consequence of a change in $\left[\mathrm{H}^{+}\right]$inside the $\mathrm{CV}$ in cases where $\mathrm{H}^{+}$can somehow enter this compartment. Ion composition inside the $\mathrm{CV}$ could, however, also indirectly be altered by changing $\left[\mathrm{H}^{+}\right]$ in the cytosol, assuming that $\mathrm{H}^{+}$gradients between the cytosol and the $\mathrm{CV}$ potentially drive numerous transport processes of major ions such as $\mathrm{Ca}^{2+}$ or $\mathrm{Mg}^{2+}$ (Langer et al., 2006; Mackinder et al., 2010, 2011). 
The prominent influence of $\left[\mathrm{H}^{+}\right]$on malformations observed in the investigated E. huxleyi strain raises the question whether this particular carbonate chemistry parameter is also responsible for observed malformations in other coccolithophore species and E. huxleyi strains. Langer and Bode (2011) examined coccolith malformation of Calcidiscus leptoporus in response to various carbonate system parameters. In contrast to our findings, they identified $\mathrm{CO}_{2}$ as the key carbonate chemistry parameter causing malformations, which suggests that the control mechanisms of coccolith formation are affected by different carbonate system parameters on a species level. A comparison on the strain level is not possible because there is no such data on different strains of the same species available so far. The only information available at the moment is that the carbonate chemistry conditions at which malformations start to appear differ between different strains of E. huxleyi (Langer et al., 2011). Clearly, this does not mean that the key carbonate chemistry parameter causing malformations differs between E. huxleyi strains but it shows that sensitivities to changes in carbonate chemistry do.

\subsection{Influence of individual carbonate chemistry param- eters on coccolith size}

There is experimental evidence that $\mathrm{HCO}_{3}^{-}$is the principal inorganic carbon source utilised for calcification (Sikes et al., 1980; Buitenhuis et al., 1999). The dependence of calcification on $\mathrm{HCO}_{3}^{-}$seems to be reflected in DSA, DSL, and DSW which increased comparably in all experiments from low to high $\left[\mathrm{HCO}_{3}^{-}\right]$up to $\sim 2000 \mu \mathrm{mol} \mathrm{HCO}_{3}^{-} \mathrm{kg}^{-1}$. The close correlation to $\left[\mathrm{HCO}_{3}^{-}\right]$makes this ion a key candidate responsible for at least some of the pronounced increase in DSA, DSL, and DSW observed within that range (Fig. 5a-d; data for DSW not shown). Next to $\mathrm{HCO}_{3}^{-}, \mathrm{H}^{+}$ is another factor with potential influence. $\mathrm{H}^{+}$might be particularly important in the high $f \mathrm{CO}_{2}$ range of the constant TA experiment. Here, the observed decrease in size cannot be explained by $\left[\mathrm{HCO}_{3}^{-}\right]$since the concentration of this ion is still increasing whereas DSA, DSL, and DSW are already decreasing (Fig. 5d). A potential negative effect of very high $\left[\mathrm{H}^{+}\right]$seems possible since $\mathrm{H}^{+}$has already been shown to be detrimental to calcification rates above certain thresholds (Bach et al., 2011). In contrast to $\mathrm{HCO}_{3}^{-}$and $\mathrm{H}^{+}$, the influence of $\mathrm{CO}_{2}$ is of minor importance (Fig. 5a-d; data for DSW not shown). DSA, DSL, and DSW clearly decreased in the constant $\mathrm{CO}_{2}$ experiment. If $\mathrm{CO}_{2}$ was of primary importance in determining these morphological parameters, then DSA, DSL, and DSW would have remained constant in the constant $\mathrm{CO}_{2}$ experiment. The fourth parameter with possible influence is $\mathrm{CO}_{3}^{2-} \cdot \mathrm{CO}_{3}^{2-}$ is of high importance for the dissolution of calcite due to its influence on the calcium carbonate saturation state of seawater. Whether it is of direct physiological influence on coccolith formation is more difficult to assess because relatively little is known about the possibilities of cells to transport $\mathrm{CO}_{3}^{2-}$ across membranes.
Such transporters have so far not been identified (Mackinder et al., 2010). In our study, a differentiation between $\mathrm{HCO}_{3}^{-}$ and $\mathrm{CO}_{3}^{2-}$ is only possible in the constant TA experiment because they positively correlate in all others (Fig. 1). In the constant TA experiment, DSA, DSL and DSW correlate with $\left[\mathrm{HCO}_{3}^{-}\right]$and not $\left[\mathrm{CO}_{3}^{2-}\right]$ in the low $f \mathrm{CO}_{2}$ range. This indicates that increasing $\left[\mathrm{CO}_{3}^{2-}\right]$ is not likely to be responsible for increasing DSA, DSL and DSW.

CAL and CAW displayed no clear change in response to changing carbonate chemistry except for the very low $f \mathrm{CO}_{2}$ range in the constant TA experiment where they tended to decrease (Fig. 5f, data for CAW not shown). As discussed in Sect. 4.2, coccolith formation starts with the construction of an organic base plate on which calcite crystals start to grow in a radial direction. The dimensions of the central area of the coccolith largely reflect the dimensions of the organic base plate (Westbroek et al., 1984; Young, 1994). Hence, if the dimensions of the central area are affected to a lesser extent by changing carbonate chemistry, so are the dimensions of the organic base plate. Accordingly, we hypothesize that changing carbonate chemistry primarily influences crystal growth and not so much formation and size of the organic base plate.

\subsection{Correlation between calcification rates and coccolith weight}

Changes in cellular calcification rates can be expressed in three different ways: (1) a change in coccolith weight at constant coccolith exocytosis rate, (2) a change in coccolith exocytosis rate at constant coccolith weight, and (3) a simultaneous change in coccolith weight and exocytosis rate. Results presented in Fig. 6a and b support the third option, indicating that a correlation between calcification rates and coccolith weight exists in the investigated $E$. huxleyi strain. This suggests that measurements of coccolith weight could potentially be useful to reconstruct calcification rates. Nevertheless, this correlation bears uncertainties which should be considered before extrapolating these results to the field.

There is the high genetic variability between different coccolithophore species and even strains of the same species (e.g. Brand, 1982; Young and Westbroek, 1991; IglesiasRodriguez et al., 2006). It has been demonstrated that this variability translates to species- and strain-specific sensitivities of calcification rates to simulated ocean acidification (Langer et al., 2006, 2009). Genetically based differences in sensitivities to changes in carbonate chemistry could also be reflected in strain- and species-specific coupling between $\mathrm{CaCO}_{3}$ production and coccolith weight. On the other hand, differences in sensitivities within a certain $f \mathrm{CO}_{2}$ range do not necessarily result in a fundamentally different response when a broad $f \mathrm{CO}_{2}$ range, at which the strain is able to calcify, is considered. It has been proposed that the general response of presumably all E. huxleyi strains to a broad $f \mathrm{CO}_{2}$ range is similar (resembling an optimum curve), even though there are strain-specific differences within distinct parts of 
the whole optimum curve (Bach et al., 2011). Therefore, it could be possible that the positive physiological correlation between $\mathrm{CaCO}_{3}$ production rates and coccolith weight, that has been found for the investigated E. huxleyi strain, also emerges in other strains and potentially even in other coccolithophore species, at least when a relatively wide range of carbonate chemistry conditions is considered.

Another factor to consider is the driving force that causes changes in $\mathrm{CaCO}_{3}$ production rates and coccolith weight. Aside from carbonate chemistry, temperature can influence $\mathrm{CaCO}_{3}$ production. A temperature rise from 10 to $20^{\circ} \mathrm{C}$ increases $\mathrm{CaCO}_{3}$ production rates in $E$. huxleyi by more than $40 \%$ under ambient carbonate chemistry conditions (Langer et al., 2007), whereas it influences coccolith size (and therefore most likely also coccolith weight) only marginally (Watabe and Wilbur, 1966; Fielding et al,. 2009). Under this consideration it seems possible that the physiological coupling between $\mathrm{CaCO}_{3}$ production and coccolith weight is not universal but rather specific for changes induced by the carbonate chemistry conditions.

Furthermore, it is important to keep in mind that the correlation between coccolith weight and $\mathrm{CaCO}_{3}$ production rates given in Fig. 6a is derived from monoclonal culture experiments which exclude ecological processes. This is a limitation of the correlation because, in a natural E. huxleyi assemblage, changing carbonate chemistry could not only directly affect the cell physiology but also induce a shift in the dominant strain. A strain shift in a natural assemblage can change both mean calcification rate and mean coccolith weight, but these two factors do not necessarily have to be correlated to each other as implied in Fig. 6a. The unknown role of ecological processes should therefore clearly be considered before using the correlation between calcification rates and coccolith weight to interpret field data.

\subsection{Environmental control of coccolith size and weight}

There are two different mechanisms how an environmental change in the habitat of an E. huxleyi assemblage can induce a change of mean coccolith size and/or weight:

1. The changing environmental factor (e.g. temperature) induces a dominance shift in the assemblage towards an E. huxleyi strain or morphotype which forms coccoliths of different size and weight than the one dominant initially. Here, the influence is indirect and in the following termed "ecologically" driven change in coccolith size and/or weight. Morphotype-specific size and weight variations range from $2.5-5 \mu \mathrm{m}$ and $0.6-4.6 \mathrm{pg}$, respectively (Young and Ziveri, 2000). Coccoliths of morphotye $\mathrm{R}$ or over-calcified coccoliths of morphotype $\mathrm{A}$ are usually relatively heavy, whereas the delicate coccoliths of morphotype B (pujosiae) are particularly large (Young and Ziveri, 2000; Young et al., 2003).
2. A change in some environmental factor directly affects the physiology of the dominant E. huxleyi strain or morphotype present in the assemblage, thereby directly causing a change in mean size and weight (in the following termed "physiologically" driven change in coccolith size and/or weight). Environmental factors known to modify size and/or weight are salinity (Green et al., 1998; Bollmann and Herrle, 2007; Fielding et al., 2009), temperature (Watabe and Wilbur, 1966), nutrient availability (Batvik et al., 1997; Paasche, 1998), growth stage (Young and Westbroek, 1991), seasonality (Triantaphyllou et al., 2010) and carbonate chemistry (Iglesias-Rodriguez et al., 2008; Halloran et al., 2008; Beaufort et al., 2011; this study). In the following we discuss the potential of some of these environmental factors (salinity, temperature and carbonate chemistry) to induce either ecologically or physiologically driven change in coccolith size and/or weight of E. huxleyi.

Increasing salinity was shown to positively influence the size of E. huxleyi coccoliths (e.g. Green et al., 1998). Fielding et al. (2009) reported a $30 \%$ increase in DSW in a salinity gradient ranging from 26 to 41 under constant culture conditions, indicating that salinity has a relatively high physiological influence on coccolith size. However, whether changing salinity also has the potential to cause a shift in the dominant morphotype in a natural E. huxleyi assemblage is unknown. An ecological influence seems conceivable in coastal environments with comparatively large salinity variations, while it is less likely in the more stable conditions found in the open ocean.

Temperature seems to have a small physiological influence on E. huxleyi coccolith size. Watabe and Wilbur (1966) observed no change in DSL from 7 to $18^{\circ} \mathrm{C}$ and only a minor decrease of about $10 \%$ from 18 to $27^{\circ} \mathrm{C}$. This is largely in line with results by Fielding et al. (2009) who found no detectable influence between 10 and $20^{\circ} \mathrm{C}$. In contrast to that, the ecological influence of temperature on coccolith size could be considerably larger. It is likely that coccolithophores are adapted to the mean temperature of their natural habitat (Buitenhuis et al., 2008). In case the mean temperature in a given area changes, another strain or morphotype (potentially having a different coccolith size and/or weight) could take over. A possible example where this might have been observed is given by Triantaphyllou et al. (2010) who investigated changes in E. huxleyi coccolith size in a seasonal cycle in the Aegean Sea (Eastern Mediterranean Sea). They reported a shift towards larger coccoliths during cooler winter/spring periods with one possible explanation being the dominance of another E. huxleyi strain during that time of the year.

The results presented in our study demonstrate a negligible physiological influence of carbonate chemistry on E. huxleyi coccolith size and weight within a realistic range (DIC $\sim 1800-2400$ and $f \mathrm{CO}_{2} \sim 180-1000$ (Sarmiento and 
Gruber, 2006)). However, there seems to be a high potential of changing carbonate chemistry to cause ecologically driven change in coccolith size and/or weight. In a recent investigation, Beaufort et al. (2011) concluded that carbonate chemistry conditions regulate the relative abundance of different species and morphotypes in the oceans and that species and morphotypes which form heavier coccoliths are predominantly found at sites with supposedly more favourable carbonate chemistry conditions. According to the interpretations by Beaufort et al. (2011), the carbonate chemistry has a particularly large ecological influence on coccolith weight.

Currently, the physiological influence of the environmental factors mentioned above is understood better than the ecological influence. This is probably due to the fact that physiological experiments are in most cases easier to perform and easier to evaluate than ecological data sets. However, in order to improve our understanding of what drives changes in coccolith size and weight in the oceans, it is essential to focus particularly on the ecological component since this seems to be of larger influence.

Acknowledgements. We thank Andrea Ludwig for her support on DIC measurements, Ute Schuldt and Arno Lettmann from the SEM laboratory at the Institute of Geosciences for their support during scanning electron microscopy and Luke Mackinder and Kai Lohbeck for interesting discussions about the dataset. This research was funded by the Federal Ministry of Education and Research (Bundesministerium für Bildung und Forschung; 03F0608A) in the framework of the Biological Impacts of Ocean Acidification (BIOACID) project (subproject 3.1.1 in collaboration with subproject 3.5.3).

Edited by: H. Kitazato

\section{References}

Bach, L. T., Riebesell, U., and Schulz, K. G.: Distinguishing between the effects of ocean acidification and ocean carbonation in the coccolithophore Emiliania huxleyi, Limnol. Oceanogr., 56, 2040-2050, 2011.

Batvik, H., Heimdal, B. R., Fagerbakke, K. M., and Green, J. C.: Effects of unbalanced nutrient regime on coccolith morphology and size in Emiliania huxleyi (Prymnesiophyceae), Eur. J. Phycol., 32, 155-165, 1997.

Beaufort, L. and Dollfus, D.: Automatic recognition of coccolith by dynamical neural network, Mar. Micropaleont., 51, 57-73, 2004.

Beaufort, L., Couapel, M., Buchet, N., Claustre, H., and Goyet, C.: Calcite production by coccolithophores in the south east Pacific Ocean, Biogeosciences, 5, 1101-1117, doi:10.5194/bg-5-11012008, 2008.

Beaufort, L., Probert, I., de Garidel-Thoron, T., Bendif, E. M., RuizPino, D., Metzl, N., Goyet, C., Buchet, N., Coupel, P., Grelaud, M., Rost, B., Rickaby, R. E. M., and de Vargas, C.: Sensitivity of coccolithophores to carbonate chemistry and ocean acidification, Nature, 476, 80-83, 2011.
Bollmann, J. and Herrle, J. O.: Morphological variation of Emiliania huxleyi and sea surface salinity, Earth Planet. Sci. Lett., 255, 273-288, 2007.

Borman, A. H., De Jong, E. W., Huizinga, M., Kok, D. J., Westbroek, P., and Bosch, L.: The role in $\mathrm{CaCO}_{3}$ crystallization of an acid $\mathrm{Ca}^{2+}$-binding polysaccharide associated with coccoliths of Emiliania huxleyi, Eur. J. Biochem., 129, 179-183, 1982.

Bown, P. R., Lees, J. A., and Young, J. R.: Calcareous nannoplankton evolution and diversity through time, in: Coccolithophores From Molecular Processes to Global Impact, edited by: Thierstein, H. R. and Young, J. R., Springer, Heidelberg, 481-508, 2004.

Brand, L. E.: Genetic variability and spatial patterns of genetic differentiation in the reproductive rates of the marine coccolithophores Emiliania huxleyi and Gephyrocapsa oceanica, Limnol. Oceanogr., 27, 236-245, 1982.

Buitenhuis, E. T., de Baar, H. J. W., and Veldhuis, M. J. W.: Photosynthesis and calcification by Emiliania huxleyi (Prymnesiophyceae) as a function of inorganic carbon species, J. Phycol., 35, 949-959, 1999.

Buitenhuis, E. T., Pangerc, T., Franklin, D. J., Le Quéré, C., and Malin, G.: Growth rates of six coccolithophorid strains as a function of temperature, Limnol. Oceanogr., 53, 1181-1185, 2008.

De Jong, E. W., Bosch, L., and Westbroek, P.: Isolation and characterization of a $\mathrm{Ca}^{2+}$-binding polysaccharide associated with coccoliths of Emiliania huxleyi (Lohmann) Kamptner, Eur. J. Biochem., 70, 611-621, 1976.

Dickson, A. G., Afghan, J. D., and Anderson, G. C.: Reference materials for oceanic $\mathrm{CO}_{2}$ analysis: A method for the certification of total alkalinity, Mar. Chem., 80, 185-197, 2003.

Dickson, A. G., Sabine, C. L., and Christian, J. R.: Guide to best practices for ocean $\mathrm{CO}_{2}$ Measurements, PICES Special Publication, Sidney, 2007.

Didymus, J. M., Young, J. R., and Mann, S.: Construction and morphogenesis of the chiral ultrastructure of coccoliths from the marine alga Emiliania huxleyi, Proc. R. Soc. London B, 258, $237-$ 245, 1994.

Fagerbakke, K., M., Heldal, M., Norland, S., Heimdal, B. R., and Batvik, H.: Emiliania huxleyi. Chemical composition and size of coccoliths from enclosure experiments and a Norwegian fjord, Sarsia, 79, 349-355, 1994.

Fielding, S. R., Herrle, J. O., Bollmann, J., Worden, R. H., and Montagnes, D. J. S.: Assessing the applicability of Emiliania huxleyi coccolith morphology as a sea-surface salinity proxy, Limnol. Oceanogr., 54, 1475-1480, 2009.

Gattuso, J. P., Gao, K., Lee, K., Rost, B. and Schulz, K. G.: Approaches and tools to manipulate the carbonate chemistry, in: Guide for best practices for ocean acidification research and data reporting, edited by: Riebesell, U., Fabry, V., Hansson, L., and Gattuso, J. P., Publications Office of the European Union, 41-52, 2010.

Green, J. C., Heimdal, B. R., Paasche, E., and Moate, R.: Changes in calcification and the dimensions of coccoliths of Emiliania huxleyi (Haptophyta) grown at reduced salinities, Phycologia, 37, 121-131, 1998.

Guillard, R. R. and Ryther, J. H.: Studies of marine planktonic diatoms. I. Cyclotella nana Hustedt, and Detonula confervacea (cleve) Gran, Can. J. Microbiol., 8, 229-239, 1962. 
Hagino, K., Bendif, E. M., Young, J. R., Kogame, K., Probert, I., Takano, Y., Horiguchi, T. de Vargas, C., and Okada, H.: New evidence for morphological and genetic variation in the cosmopolitan coccolithophore Emiliania huxleyi (Prymnesiophyceae) from the COX1b-ATP4 genes, J. Phycol., 47, 1164-1176, 2011.

Halloran, P. R., Hall, I. R., Colmenero-Hidalgo, E., and Rickaby, R. E. M.: Evidence for a multi-species coccolith volume change over the past two centuries: understanding a potential ocean acidification response, Biogeosciences, 5, 1651-1655, doi:10.5194/bg-5-1651-2008, 2008.

Hansen, H. P. and Koroleff, F.: Determination of nutrients, in: Methods of seawater analysis, edited by: Grasshoff, K., Kremling, K., and Ehrhardt, M., Wiley-VCH, 159-228, 1999.

Henriksen, K. and Stipp, S. L., S.: Controlling Biomineralization: The Effect of Solution Composition on Coccolith Polysaccharide Functionality, Cryst. Growth Des., 9, 2088-2097, 2009.

Henriksen, K., Stipp, S. L. S., Young, J. R., and Marsh, M. E.: Biologic control on calcite crystallization: AFM investigation of coccolith polysaccharide function, Am. Mineralogist, 89, 17091716, 2004.

Holligan, P. M., Fernandez, E., Aiken, J., Balch, W. M., Boyd, P., Burkill, P. H., Finch, M., Groom, S. B., Malin, G., Muller, K., Purdie, D. A., Robinson, C., Trees, C. C., Turner, S. M., and van der Wal, P.: A biogeochemical study of the coccolithophore, Emiliania huxleyi, in the North Atlantic, Global Biogeochem. Cy., 7, 879-900, 1993.

Honjo, S.: Coccoliths: Production, transportation and sedimentation, Mar. Micropaleontol., 1, 65-79, 1976.

Iglesias-Rodriguez, M. D., Schofield, O. M., Batley, J., Medlin, L. K., and Hayes, P. K.: Intraspecific genetic diversity in the marine coccolithohore Emiliania huxleyi (Prymnesiophyceae): The use of microsatellite analysis in marine phytoplankton population studies, J. Phycol., 42, 526-536, 2006.

Iglesias-Rodriguez, M. D., Halloran, P. R., Rickaby, R. E. M., Hall, I. R., Colmenero-Hidalgo, E., Gittins, J. R., Green, D. R. H., Tyrrell, T., Gibbs, S. J., von Dassow, P., Rehm, E., Armbrust, E. V., and Boessenkool, K. P.: Phytoplankton calcification in a high- $\mathrm{CO}_{2}$ world, Science, 320, 336-340, doi:10.1126/science.1154122, 2008.

Kaffes, A., Thoms, S., Trimborn, S., Rost, B., Langer, G., Richter, K.-U., Köhler, A., Norici, A., and Giordano, M.: Carbon and nitrogen fluxes in the marine coccolithophore Emiliania huxleyi grown under different nitrate concentrations, J. Exp. Mar. Biol. Ecol., 393, 1-8, 2010.

Kester, D., Duedall, I. W., Connors, D. N., and Pytkowicz, R. M.: Preparation of artificial seawater, Limnol. Oceanogr., 1, 176179, 1967.

Langer, G. and Bode, M.: $\mathrm{CO}_{2}$ mediation of adverse effects of seawater acidification in Calcidiscus leptoporus, Geochem. Geophy. Geosy., 12, Q05001, doi:10.1029/2010GC003393, 2011.

Langer, G., Geisen, M., Baumann, K.-H., Kläs, J., Riebesell, U., Thoms, S. and Young, J. R.: Species-specific responses of calcifying algae to changing seawater carbonate chemistry, Geochem. Geophy. Geosy., 7, Q09006, doi:10.1029/2005GC001227, 2006.

Langer, G., Gussone, N., Nehrke, G., Riebesell, U., Eisenhauer, A., and Thoms, S.: Calcium isotope fractionation during coccolith formation in Emiliania huxleyi: Independence of growth and calcification rate, Geochem. Geophys. Geosys., 8, Q05007, doi:10.1029/2006GC001422, 2007.
Langer, G., Nehrke, G., Probert, I., Ly, J., and Ziveri, P.: Strain-specific responses of Emiliania huxleyi to changing seawater carbonate chemistry, Biogeosciences, 6, 2637-2646, doi:10.5194/bg-6-2637-2009, 2009.

Langer, G., De Nooijer, L. J., and Oetjen, K.: On the role of the cytoskeleton in coccolith morphogenesis: the effect of cytoskeleton inhibitors, J. Phycol., 46, 1252-1256, 2010.

Langer, G., Probert, I., Nehrke, G., and Ziveri, P.: The morphological response of Emiliania huxleyi to seawater carbonate chemistry changes: an inter-strain comparison, J. Nannoplankton Res., 32, 29-34, 2011.

LaRoche, J., Rost, B., and Engel, A.: Bioassay, batch culture and chemostat experimentation, in: Guide for best practices for ocean acidification research and data reporting, edited by: Riebesell, U., Fabry, V., Hansson, L., and Gattuso, J.-P., Publications Office of the European Union, 81-94, 2010.

Lewis, E. and Wallace, D. W. R.: Program Developed for $\mathrm{CO}_{2}$ System Calculations ORNL/CDIAC-105, Carbon Dioxide Information Analysis Centre, Oak Ridge National Laboratory, US Department of Energy, 1998.

Mackinder, L. C. M., Wheeler, G., Schroeder, D., Riebesell, U., and Brownlee, C.: Molecular mechanisms underlying calcification in coccolithophores, Geomicrobiol. J., 27, 585-595, 2010.

Mackinder, L. C. M., Wheeler, G., Schroeder, D., von Dassow, P., Riebesell, U., and Brownlee, C.: Expression of biomineralization-related ion transport genes in Emiliania huxleyi, Environ. Microbiol., 13, 3250-3265, 2011.

Marsh, M. E.: Polyanion-mediated mineralization - assembly and reorganization of acidic polysaccharides in the Golgi system of a coccolithophorid alga during mineral deposition, Protoplasma, 177, 108-122, 1994.

Moore, T. S., Dowell, M. D., and Franz, B. A.: Detection of coccolithophore blooms in ocean color satellite imagery: A generalized approach for use with multiple sensors, Remote Sens. Environ., 117, 249-263, 2012.

Müller, M. N., Schulz, K. G., and Riebesell, U.: Effects of long-term high $\mathrm{CO}_{2}$ exposure on two species of coccolithophores, Biogeosciences, 7, 1109-1116, doi:10.5194/bg-7-1109-2010, 2010.

Paasche, E.: Roles of nitrogen and phosphorus in coccolith formation in Emiliania huxleyi (Prymnesiophyceae), Eur. J. Phycol., 33, 33-42, 1998.

Paasche, E.: A review of the coccolithophorid Emiliania huxleyi (Prymnesiophyceae), with particular reference to growth, coccolith formation, and calcification-photosynthesis interactions., Phycologia, 40, 503-529, 2002.

Ploug, H., Iversen, M. H., Koski, M., and Buitenhuis, E. T.: Production, oxygen respiration rates, and sinking velocity of copepod fecal pellets: Direct measurements of ballasting by opal and calcite, Limnol. Oceanogr., 53, 469-476, 2008.

Raffi, I., Backman, J., Fornaciari, E., Pälike, H., Rio, D., Lourens, L., and Hilgen, F.: A review of calcareous nannofossil astrobiochronology encompassing the past 25 million years, Quat. Sci. Rev., 25, 3113-3137, 2006.

Raven, J. A., Caldeira, K., Elderfield, H., Hoegh-Guldberg, O., Liss, P., Riebesell, U., Shepherd, J., Turley, C., and Watson, A.: Ocean acidification due to increasing atmospheric carbon dioxide, 60, Policy Document 12/05, The Royal Society, London, 2005.

Riebesell, U. and Tortell, P. D.: Effects of ocean acidification on pelagic organisms and ecosystems, in: ocean acidification, edited 
by: Gattuso, J.-P. and Hansson, L., Oxford University Press, Oxford, 99-121, 2011.

Riebesell, U., Zondervan, I., Rost, B., Tortell, P. D., Zeebe, R., and Morel, M. F. M.: Reduced calcification of marine plankton in response to increased atmospheric $\mathrm{CO}_{2}$, Nature, 407, 364-367, 2000.

Roy, R. N., Roy, L. N., Vogel, K. M., Porter-Moore, C., Pearson, T., Good, C. E., Millero, F. J., and Campbell, D. C.: Thermodynamics of the dissociation of boric acid in seawater at S 535 from 0 degrees C to 55 degrees C, Mar. Chem., 44, 243-248, 1993.

Sarmiento, J. L. and Gruber, N. (Eds.): Ocean biogeochemical dynamics, Cambridge University Press, Cambridge, United States of America, 2006.

Schiebel, R., Brupbacher, U., Schmidko, S., Nausch, G., Waniek, J. J., and Thierstein, H.-R.: Spring coccolithophore production and dispersion in the temperate eastern North Atlantic Ocean, J. Geophys. Res., 116, C08030, doi:10.1029/2010JC006841, 2011.

Schulz, K. G., Riebesell, U., Bellerby, R. G. J., Biswas, H., Meyerhöfer, M., Müller, M. N., Egge, J. K., Nejstgaard, J. C., Neill, C., Wohlers, J., and Zöllner, E.: Build-up and decline of organic matter during PeECE III, Biogeosciences, 5, 707-718, doi:10.5194/bg-5-707-2008, 2008

Sikes, C. S., Roer, R. D., and Wilbur, K. M.: Photosynthesis and coccolith formation: inorganic carbon sources and net inorganic reaction of deposition, Limnol. Oceanogr., 25, 248-261, 1980.

Stoll, M. H. C., Bakker, K., Nobbe, G. H., and Haese, R. R.: Continuous-flow analysis of dissolved inorganic carbon content in seawater, Anal. Chem., 73, 4111-4116, 2001.

Suffrian K., Schulz, K. G., Gutowska, M., Riebesell, U., and Bleich, M.: Cellular pH measurements in Emiliania huxleyi reveal pronounced membrane proton permeability, New Phytol., 190, 595-608, 2011.

Thierstein, H. R., Geitzenauer, K., R., Molfino, B., and Shackleton, N. J.: Global synchroneity of late quaternary coccolith datum levels: validation by oxygen isotopes, Geology, 5, 400-404, 1977.

Triantaphyllou, M., Dimiza, M., Krasakopoulou, E., Malinverno, E., Lianou, V., and Souvermezoglou, E.: Seasonal variation in Emiliania huxleyi coccolith morphology and calcification in the Aegean Sea (Eastern Mediterranean), Geobios, 43, 99-110, 2010.

Tyrell, T. and Merico, A.: Emiliania huxleyi: bloom observations and the conditions that induce them, in: Coccolithophores from molecular processes to global impact, edited by: Thierstein, H.R. and Young, J. R., Springer, Heidelberg, 2004.
Tyrrell, T. and Young, J. R.: Coccolithophores, in: Encyclopedia of Ocean Sciences, edited by: Steele, J. H., Turekian, K. K., and Thorpe, S. A., Academic Press, San Diego, 3568-3576, 2009.

van der Wal, P., De Jong, E. W., Westbroek, P., De Bruijn, W. C., and Mulder-Stapel, A. A.: Ultrastructural polysaccharide localization in calcifying and naked cells of the coccolithophorid Emiliania huxleyi, Protoplasma, 118, 157-168, 1983.

Watabe, N. and Wilbur, K. M.: Effects of temperature on growth, calcification and coccolith form in Coccolithus huxleyi (Coccolithineae), Limnol. Oceanogr., 11, 567-575, 1966.

Westbroek, P., De Jong, E. W., Van Der Wal, P., Borman, A. H., De Vrind, J. P. M., Kok, D., De Bruijn, W. C., and Parker, S. B.: Mechanism of calcification in the marine alga Emiliania huxleyi, Philos. Trans. R. Soc. Lond. B, 304, 435-444, 1984.

Westbroek, P., Young, J. R., and Linschooten, K.: Coccolith production (biomineralisation) in the marine alga Emiliania huxleyi, J. Protozool., 36, 368-373, 1989.

Young, J. R.: Variation in Emiliania huxleyi coccolith morphology in samples from the Norwegian EHUX mesocosm experiment, 1992, Sarsia, 79, 417-425, 1994.

Young, J. R. and Westbroek, P.: Genotypic variation in the coccolithophorid species Emiliania huxleyi, Mar. Micropaleontol., 18, 5-23, 1991.

Young, J. and Ziveri, P.: Calculation of coccolith volume and its use in calibration of carbonate flux estimates, Deep Sea Res., 47, 1679-1700, 2000.

Young, J. R., Didymus, J. M., Bown, P. R., Prins, B., and Mann, S.: Crystal assembly and evolution in heterococcoliths, Nature, 356, 516-518, 1992.

Young, J. R., Davis, S. A., Bown, P. R., and Mann, S.: Coccolith ultrastructure and biomineralisation, J. Struct. Biol., 126, 195215, 1999.

Young, J. R., Geisen, M., Cros, L., Kleijne, A., Sprengel, C., Probert, I., and Østergaard, J. B.: A guide to extant calcareous nannoplankton taxonomy, J. Nannoplankton Res., 1, 1-125, 2003.

Young, J. R., Andruleit, H., and Probert, I.: Coccolith function and morphogenesis: insights from appendage-bearing coccolithophores of the family Syracosphaeraceae (Haptophyta), J. Phycol., 45, 213-26, 2009. 